\title{
Bone disease after transplantation: osteoporosis and fractures risk
}

\author{
Doença óssea pós-transplante: risco de osteoporose e fraturas
}

Carolina A. M. Kulak ${ }^{1,2}$, Victoria Z. C. Borba', Jaime Kulak Júnior ${ }^{3}$, Melani Ribeiro Custódio ${ }^{4}$

1 Endocrine Division (SEMPR), Hospital de Clinicas, Universidade Federal do Paraná (UFPR), Curitiba, PR, Brazil

${ }^{2}$ Department of Internal Medicine, UFPR, Curitiba, PR, Brazil ${ }^{3}$ Department of Obstetrics and Gynecology, UFPR, Curitiba, PR, Brazil

${ }^{4}$ Department of Internal Medicine, Nephrology Division, Universidade de São Paulo (USP), São Paulo, SP, Brazil

Correspondence to: Carolina A. M. Kulak Serviço de Endocrinologia e Metabologia, Hospital das Clínicas Universidade Federal do Paraná Av. Agostinho Leão Júnior, 285 80030-013 - Curitiba, PR, Brazil kulakjc@gmail.com

Received on Mar/9/2014 Accepted on May/28/2014

DOI: 10.1590/0004-2730000003343

\begin{abstract}
Organ transplantation is the gold standard therapy for several end-stage diseases. Bone loss is a common complication that occurs in transplant recipients. Osteoporosis and fragility fractures are serious complication, mainly in the first year post transplantation. Many factors contribute to the pathogenesis of bone disease following organ transplantation. This review address the mechanisms of bone loss including the contribution of the immunosuppressive agents as well as the specific features to bone loss after kidney, lung, liver, cardiac and bone marrow transplantation. Prevention and management of bone loss in the transplant recipient should be included in their post transplant follow-up in order to prevent fractures. Arq Bras Endocrinol Metab. 2014;58(5):484-92
\end{abstract}

Keywords

Transplantation; bone loss; osteoporosis; fractures; immunosuppressive agents

\section{RESUMO}

Transplantes de órgão é terapia padrão-ouro para várias doenças em estágio terminal. Perda óssea é uma complicação comum que ocorre em pacientes transplantados. Osteoporose e fraturas por fragilidade são complicações sérias, principalmente no primeiro ano pós-transplante. Muitos fatores podem contribuir para patogênese da doença óssea nesses pacientes. Esta revisão aborda os mecanismos de perda óssea incluindo o papel dos agentes imunossupressores, bem como os fatores específicos da perda óssea após rim, pulmão, fígado, coração e transplante de medula óssea. A prevenção e o tratamento da perda óssea nos pacientes transplantados devem ser realizados para evitar fraturas. Arq Bras Endocrinol Metab. 2014;58(5):484-92

\section{Descritores}

Transplante; perda óssea; osteoporose; fraturas; agentes imunossupressores

\section{INTRODUCTION}

$\mathrm{O}$ rgan transplantation is the gold standard treatment for several end-stage diseases. As advances in immunosuppression therapy and transplant techniques over the last decades have improved allograft and patient survival, new challenges have emerged in the management of long-term complications. Post-transplantation bone disease is a major complication present in most of patients, where low bone mineral density (BMD) increases the risk of fractures and consequently, reduces quality of life and increases mortality $(1,2)$.

In this review, the mechanism of bone loss after the organ transplantation, the therapeutic recommendations and the specific features relevant to each organ such as kidney, lung, liver, heart and bone marrow, will be addressed.

\section{Bone disease and transplant}

The abnormalities in bone metabolism after transplantation are very similar regardless of organ type, pre-existent bone disease and previous treatment. Frequently, bone loss occurs in the first year after the organ transplant, due the adverse effects of immunosuppressive drugs and in addition, due to long period of immobilization. However, it is important to note that low bone mass and fractures may antedate transplantation, which could be related to effects on the skeleton of chronic 
disease and the presence of concomitant risk factors for osteoporosis (2).

\section{MECHANISM OF BONE LOSS: THE ROLE OF IMMUNOSUPPRESSIVE DRUGS}

\section{Glucocorticoids (GCs)}

The role of GCs is well known and they are used in most immunosuppressive regimens after transplantation. In the early phase, high doses $(1 / 2 \mathrm{mg} / \mathrm{kg} /$ day during the first month, gradually reducing the dose up to $5 \mathrm{mg}$ /day for 4-6 months) are commonly used and a rapid bone loss occurs mainly in cancellous bone. The physiopathology of GCs induced bone disorder is multi-factorial. Prolonged use of GCs is associated with decreased bone formation, increased resorption and osteonecrosis, through direct and indirect effects on the activity and viability of bone effector cells, osteoblasts and osteoclasts, and osteocytes (3). GCs induce osteoblast and osteocyte apoptosis and promote osteoclastogenesis by increasing levels of RANK-L system (4). Other indirect effects of GCs also play a role in the mechanisms of bone loss such as reduced intestinal calcium absorption and renal calcium wasting and both may lead to a secondary hyperparathyroidism. Furthermore, GCs may induce a muscle weakness, which additionally delays post-transplant mobilization with subsequent worsening of bone loss. Later, during the post-transplant period, with the use of low doses of GCs, there is a recovery of osteoblast function and consequently, an increase in bone formation and recoupling of bone remodeling activity.

\section{Calcineurin inhibitors: cyclosporine $\mathrm{A}$ and tacrolimus}

Calcineurin inhibitors including cyclosporine A (CsA) and tacrolimus have been linked to osteoporosis $(5,6)$, however, their effects on the skeleton are not well defined. CsA may cause bone loss through direct effects on osteoclast leading high bone turnover. In the rat, cyclosporine causes bone loss that is associated with increased bone resorption and formation; however, other studies have failed to demonstrate this same effect in renal transplant recipients (6). It should be considered, however, that the role of cyclosporine in transplant patients has been difficult to evaluate because its effects on bone turnover may be masked by GCs. In fact, one study evaluating patients after renal transplantation who received CsA in a GC-free regimen did not show any bone loss (7). Tacrolimus (FK506), other calcineurin inhibitor, was demonstrated to cause bone loss in experimental animals, however, in contrast, in liver transplant recipients, tacrolimus has been associated with a significant higher femoral neck BMD as compared with cyclosporine, after two years of transplantation (6).

\section{Sirolimus}

Sirolimus, known as rapamycin, it is particularly useful after kidney transplant since it does not cause nephrotoxicity. In bone tissue, unlike calcineurin, sirolimus may inhibits osteoclasts differentiation and thus may be considered a bone-sparing immunosuppressive agent (8).

Others immunosuppressive agents such as mycofenolate mofetil and azathioprine, seem not to have effects in bone tissue. $(9,10)$. Figure 1 shows the action of immunosuppressive drugs in bone cells.

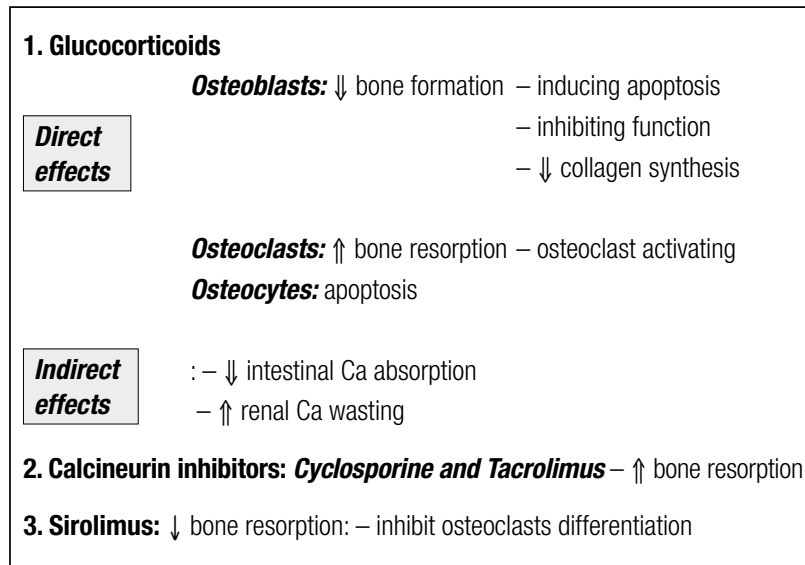

Figure 1. Immunosuppressive effects on bone.

\section{BONE DISEASE IN DIFFERENT ORGANS TRANSPLANTATION}

\section{KIDNEY transplantation}

Successful transplantation is capable of reversing many complications of the end-stage kidney disease, however, disturbances of bone and mineral metabolism, also referred to as "mineral and bone disorders" (MBD), may persist (11).

\section{Progression of biochemical abnormalities after kidney transplant}

After a successful kidney transplanted, generally metabolic abnormalities are corrected, in the following way: 


\section{Calcium}

Serum calcium levels show a steady increase and reach a plateau at month 3 to 6 . However, hypercalcemia (defined as total serum calcium $>2.62 \mathrm{mmol} / 1$ or $10.5 \mathrm{mg} / \mathrm{dL}$ ) was reported in $30 \%$ and $12 \%$ of kidney transplant recipients, 1 and 5 years after transplantation, respectively (11). There are some factors that may precipitate or worsen hypercalcemia: persistently elevated serum PTH, correction of hyperphosphatemia and improved 1,25 dihydroxyvitamin D3 production from the allograft.

\section{Phosphorus}

Hypophosphatemia is observed temporarily in up 90\% of the patients in the early post transplant period, mainly mediated by serum levels of fibroblast growth factor 23 (FGF23), with serum phosphate level between $>1.5$ and $\leq 2.3 \mathrm{mg} / \mathrm{d}$. In the late phase hypophosphatemia, PTH seems to be the unique mediator (11).

\section{5-hidroxyvitamin D (25OHD)}

Hypovitaminosis D, defined by serum levels of $25 \mathrm{OHD}$ less than $30 \mathrm{ng} / \mathrm{Ml}$ (12), is common among patients referred for kidney transplantation. It occurs mainly during the first months after transplantation and may be related to limited sunlight exposure and sun blockers use, hepatic dysfunction and use of GCs, which may increases catabolism of 25-OHD (13). Recent study demonstrated that vitamin $\mathrm{D}$ deficiency predicted a rapid decline in renal function in kidney recipient patients (14).

\section{Calcitriol (1,25 dihydroxyvitamin D)}

The recovery of renal function goes along with increase of serum calcitriol levels, however, it is common that the levels remain low during the first few months, probably due to the effect of GCs on the 1 alpha hydroxylase activity, increasing their catabolic enzyme synthesis (15).

\section{FGF23}

Serum levels of FGF23 are extremely high in dialysis patients and show a great decrease (by > 95\%) in the immediate post transplant period, normalizing after 1 year (15).

\section{PTH}

PTH levels show a rapid decrease during the first 3-6 months (approximately 50\%), attributed to a reduction of parathyroid functional mass, however, after this initial period, the reduction of PTH is more gradual (16).
However, persistently elevated levels of serum PTH, despite normalization of kidney function have been reported in up to $25 \%$ of KTRs 1 year after transplantation (11). These so-called tertiary byperparathyroidism or persistent byperparathyroidism, usually defined as elevated parathyroid hormone (PTH) levels and hypercalcemia, may cause serious problems such as soft tissue calcification, hypophosphatemia and hypercalciuria (17).

\section{Mineral and bone disorders after kidney transplantation}

The progression of bone disease after kidney transplantation is not well defined. Virtually, all patients who receive a kidney allograft suffer from some degree of preexisting bone disorders and, even after a successful kidney transplant, it seems that only few patients normalize their bone tissue (18).

\section{Patient and allograft survival}

"MBD" is associated with increased morbidity and mortality in KTRs and also associated with accelerated progression of kidney disease in these patients (19). Nephrocalcinosis, a potential clinical implication of persistent HPT, may be the major cause of disordered mineral metabolism that impaired graft survival (20).

\section{Fractures}

According to estimates, approximately $10 \%$ to $25 \%$ of all KTRs will suffer one or more fractures over their lifetime, mainly at appendicular sites such as hip, ankle and feet (15).

Although fractures rates are clearly increased in these patients, they frequently occur in the non osteoporotic by BMD criteria, questioning the use of bone densitometry by DXA to stratify fracture risk in transplant patients. However, a serial BMD measurement is useful in the evaluation of bone loss and fracture risk (15). Currently, the micro-computed tomography ( $\mu \mathrm{CT}$ ) of the distal tibia and radius seems to be useful tool for assessing bone micro architecture and fracture risk after renal transplantation $(21)$.

\section{Chronic allograft nephropathy}

Gradually failing allografts lead to post-transplantation CKD stage 3-5 leading to increased risk of worsening or de novo development of hyperparathyroidism with active vitamin $\mathrm{D}$ deficiency and metabolic disorders similar to those observed before transplantation (22). 


\section{Management of persistent hyperparathyroidism}

Whereas the persistence of HPT contributes to rapid bone loss and increased risk of fractures, the suppression of serum PTH is the primary goal. However, a severe hypercalcemia requires adjuvant interventions including the use of bisphosphonates and sometimes, in a emergency situation, calcitonin is required. Persistent HPT can be treated through surgical parathyroidectomy, or clinical treatment using cinacalcet.

\section{Cinacalcet}

In the last years, cinacalcet has been for treatment of persistent hyperparathyroidism and data from several studies indicate that it is effective. Cinacalcet successfully corrects elevate serum calcium and PTH levels with no negative effect on kidney function and apparently safe in KTRs (23). The mechanism of calcium reduction is a decreased PTH mediated calcium release from the bone, and an increased renal calcium loss due to a direct stimulation of the tubular calcium receptor $(\mathrm{CaR})$.

\section{Parathyroidectomy (PTx)}

Persistent HPT required PTx in 5\% of KTRs, however, when the cinacalcet is available, the indication is significantly reduced. In both treatment, hungry bone syndrome may occur by the decrease of PTH and some patients may have a slight increase in creatinine, especially after surgical treatment, usually reversible $(24,25)$.

\section{LUNG transplantation}

Osteoporosis is very common in patients referred for lung transplantation, especially among chronic obstructive pulmonary disease (COPD) candidates. Steroid consumption is the main risk factor (26). However, we recently demonstrated that low bone mass and microarchitecture deterioration happen in COPD patients without GCs use $(27,28)$. In a study of New Zealand, the authors found $36 \%$ and $31 \%$ of osteopenia and osteoporosis for lung candidates. Besides that, pre-transplant BMD was the major predictor for developing osteopenia or osteoporosis after transplantation (29). A cohort of 64 patients with COPD, candidates for lung transplantation, showed a $84,4 \%$ of low bone mass, with lower exercise capacity $\left(\begin{array}{lll}P & 0 & .023\end{array}\right)$ and a higher BODE index $\left(\begin{array}{lll}P & 0 & .002\end{array}\right)$ compared to patients without low bone mass.

Pre-transplantation lower BMD and longer prior glucocorticoid therapy were correlated to the incidence of fractures. Spira and cols. evaluated BMD in 28 patients prior and 6 to 12 months post lung transplantation. There was a $5 \%$ reduction in BMD of both lumbar spine and femoral neck, which was associated with cumulative steroid dose after transplantation. In addition, $18 \%$ sustained osteoporotic fractures, despite vitamin $\mathrm{D}$ and calcium supplementation (30). Prospective studies have also demonstrated changes in bone mass and fractures incidence in patients who have received a lung transplant (29). Rates of bone loss at the lumbar spine and femoral neck range from $2 \%$ to $5 \%$ in the first year after lung transplantation, respectively. In addition, fracture rates also are high, ranging from $18 \%$ to $37 \%$ during the first year, even in those patients who received antireabsorptive therapy. Osteoporosis screening prior to lung transplantation should be performed to identify high-risk subjects for fracture and allow for intervention.

\section{CARDIAC transplantation}

The most rapid rate of bone loss after cardiac transplantation also occurs during the first year. The hallmarks of osteoporosis after cardiac transplantation are the high rate of bone loss. BMD decreases 3 to $10 \%$ at the lumbar spine and 6 to $11 \%$ at the femoral neck, then seems to stabilize during the second year and may even increase after the third year (1). BMD however, has been shown not to be efficient to identify bone fragility after heart transplantation. In a study with 157 patients after 10 years of cardiac transplantation with BMD and spine $\mathrm{X}$ rays, the authors observed vertebral fractures by spine $\mathrm{x}$-ray in $40 \%$ of subjects, while osteoporosis by DXA was present only in $13 \%$ of the spine and in $25 \%$ of hip scans. This finding suggests that BMD or at least the standard densitometric criteria, is unreliable to identify bone fragility after cardiac transplantation (31).

Vertebral fractures have been reported to occur from 14 to $36 \%$ during the first post transplantation year and 22 to $35 \%$ of long-term cardiac transplant recipients (32).

Bone resorption markers are increased in the initial period after transplantation whereas bone formation marker (osteocalcin) is reduced (1). The increase of resorption may be associated with CsA-induced renal insufficiency and resultant secondary hyperparathyroidism. In general, bone formation markers return to normal by 6 to 12 months after cardiac transplantation. Serum osteoprotegerin declines during immunosuppressive therapy and accounted for $67 \%$ of the variance 
of lumbar spine bone density changes during the first 6 months post-transplantation (33). A new concern exist regarding the interference of bone loss at bone acquisition in kids after heart transplantation (34). In a histomorphometric study of nineteen children after solid organ transplantation (kidney, liver and heart) showed low trabecular bone volume in $32 \%$ and decreased trabecular thickness in 74\%, high bone turnover was present in $37 \%$ and low turnover in $32 \%$. The authors observed a great heterogeneity in the histological findings between groups, with the abnormal turnover rate and the thin trabeculae explaining the increased fracture risk in the pediatric solid organ transplant recipients (35).

One study observed that after 10 to 20 years following heart transplantation, patients present similar physical health to various chronic illnesses. However, there is a concern on the side effects of medications, renal insufficiency, osteoporosis-associated pain, cortisoneinduced myopathy and risk for tumors, besides that, they have an increase in emotional well-being (36).

\section{LIVER transplantation}

A rate from $12 \%$ to $55 \%$ of patients may have osteoporosis before liver transplantation as a result of their underlying chronic hepatic disease (37). It has been demonstrated that the bone health before transplantation may be a predictive factor of bone loss and fracture after the liver is transplanted (38). In fact, prospective studies show that the risk of post-transplantation bone loss and fractures were related to age, pre-transplantation BMD and previous vertebral fracture as well as menopause status $(39,40)$. Bone turnover has been reported to be low in many patients with liver failure; however, there is conversion to a high turnover state after liver transplantation that persists afterward. The increase in bone turnover may result from resolution of cholestasis or hypogonadism, increased PTH secretion, or CsA or FK506 administration. Significant increase in osteoprotegerin and RANK-L levels demonstrated during the first 2 weeks after liver transplantation provide further evidence of high bone turnover state. Osteoporosis remains a potential complication of liver transplantation, although its incidence may be significantly reduced by the use of lower doses of GCs. The progression of bone loss seen after liver transplantation is similar to that following lung and cardiac transplantation, being more severe in the first 6 months. One bone histomorphometry study showed that bone loss stops around
6 month, followed by a gain of bone mass, mainly at cancellous bone, in the first 2 years after the liver transplantation (39). This increase in BMD is significant higher among premenopausal than perimenopausal and postmenopausal women, probably due the protective estrogen effect to the skeleton (40). The fractures occur mainly in the 6-12 months following the transplantation, with rates ranging from $24-65 \%$; the ribs and vertebrae are the most common sites. Treatment with bisphosphonate along with calcium and vitamin D before the transplant has been demonstrated to prevent the bone loss and the high rates of fractures following liver transplantation. In this regards, one study documented a decrease in the incidence of clinical fractures during the period 1998-2008, probably due to the use of bisphosphonates to high-risk patients and also due the use of lower doses of immunosuppressors (41).

\section{Bone marrow transplantation}

Bone marrow transplant (BMT) recipients have many known risk factors for bone loss after transplantation. The bone disease following BMT differs from other forms of post-transplantation osteoporosis mainly because the recipients are usually younger and therefore the underlying hematologic disease as well as the chemotherapeutic drugs have an impact on bone accrual growth and gonadal function (42). In addition, other features such as nutritional status and vitamin D may contribute to bone loss in these patients. In regard to vitamin $\mathrm{D}, \mathrm{A}$ marked decline in the serum levels of 1,25-dihydroxyvitamin D3 and 25-hydroxyvitamin D3 in the course of allogeneic BMT was observed. The pattern of bone loss after BMT is characteristic because the bone loss is greatest at the proximal femur than the lumbar spine. During the first year, the rate of bone loss may occur from 3 to $5,9 \%$ at the lumbar spine and 8,5 to $12 \%$ at the femoral neck (43). Increased osteoclast activity due an increase in the ratio of receptor activator of the nuclear factor-k $\beta$ ligand (RANKL) to osteoprotegerin and the presence of high levels of bone marrow interleukin- 6 has been proposed to be related to this expressive rate of bone loss. In this regard, bone resorption markers were shown to increase over the first 6 months after BMT in pediatric patients (44). However, bone formation is decreased characterizing an uncoupling of bone remodeling.

Chronic graft versus host disease (GVHD) affects $30-60 \%$ of patients after BMT and is treated with high 
doses of GC, which contributes to bone loss in BMT recipients. In general, the bone loss tend to stop after 12 months following transplantation and may occur a recover of lumbar spine BMD lumbar spine within 48 months, however this recover is not seen at the femur since the bone loss is greater at this site. In addition, low BMD was associated with insulin resistance (45).

Randomized trials have been conducted to assess the effectiveness of intravenous bisphosphonate in preventing bone loss after BMT $(46,47)$. In a study with 116 patients, pamidronate along with calcium and calcitriol markedly reduced bone loss, but did not completely prevent it (46). Further, the effects of pamidronate at the bone were seen mainly at those patients receiving higher doses of immunosuppressive. In addition, after stopping pamidronate, most BMD benefits were lost. A short- term zoledronic acid treatment, three monthly doses of $4 \mathrm{mg}$ intravenous, improved both lumbar spine and femur neck BMD in transplanted patients mainly in those who presented at high risk for rapid bone loss.

\section{PREVENTION AND MANAGEMENT OF TRANSPLANTATION BONE DISEASE}

\section{Pre-transplantation evaluation}

An assessment of BMD and some parameters of bone and mineral metabolism should be performed prior to the organ transplantation. This pre-transplant evaluation is helpful to select patients who would benefit from immediate therapy and conditions such as hypogonadism, vitamin D deficiency and secondary hyperparathyroidism should be corrected. The therapy, when indicated, is similar to the treatment of post menopausal osteoporosis, except to the renal failure patients where the treatment is still controversial and a previous bone biopsy is recommended (48) (Table 1). Furthermore, patients must be encouraged to modify lifestyle factors with adverse effects on the skeleton, such as immobilization, smoking and alcohol abuse.

Table 1. Indications for bone biopsy

\begin{tabular}{l} 
1. Symptoms of bone pain, muscular weakness without correlations to \\
laboratorial findings \\
2. Fragility fractures \\
3. For diagnose of osteomalacia \\
4. Severe osteoporosis with indication for antiresorptive therapy, however with \\
low PTH, being difficult to rule out adynamic bone disease \\
\hline
\end{tabular}

\section{After transplantation evaluation}

Since the loss of bone mass and fracture risk is highest soon after transplant, therapeutic and preventive measures should be adopted early, and perhaps the most important is the use of low-dose of GCs in a shortest possible period.

\section{Vitamin D}

Hypovitaminosis D, both insufficiency and deficiency, affect $59 \%$ to $91 \%$ of transplant patients and may persist during years after transplantation and vitamin $\mathrm{D}$ supplementation with colecalciferol is indicated aiming to normalize $25 \mathrm{OH}$ vitamin D levels. In addition, administration of calcitriol in some cases of secondary hyperparathyroidism is also recommended (33).

\section{Antiresorptive agents}

\section{Bisphosphonates}

Bisphosphonates decrease bone reabsorption and improve BMD at lumbar spine and femoral neck in GCs patients. However, no date exist to support bisphosphonate treatment to reduce fracture risk in this population.

Studies using both intravenous and oral bisphosphonates have shown they are effective to prevent bone loss after transplantation $(47,49,50)$. Similarly, studies demonstrated the efficacy of intravenous ibandronate, zolendronic acid and of pamidronate in the prevention of bone loss after renal, heart, lung, liver and bone marrow transplant recipients, independently of the time following the transplantation $(47,49)$. A randomized trial comparing alendronate and calcitriol in patients directly after cardiac transplantation found that both regimens prevent bone loss at the LS and hip when compared with reference subjects who received only calcium and vitamin $\mathrm{D}(5 \mathrm{l})$.

Palmer and cols. have revealed that vitamin D analogues and bisphosphonates improve BMD loss in KTRs. Recently, a study showed that the combination therapy with vitamin $\mathrm{D}$ and bisphosphonates was the most effective regimen to improve BMD of these patients. The bisphosphonates prescription in KTRs has some particularity: patients with normal renal function and presumed increased bone resorption, based on serum PTH and alkaline phosphatase levels, the use of bisphosphonates is recommended for a short time. However, in patients with presumed low bone turn- 
over, bisphosphonates are contraindicated (8). Often makes difficult to decision due the lack of validation of bone densitometry (DXA) in chronic kidney disease, as DXA cannot differentiate between calcium accumulation in the bone and that surrounding soft tissue. Maybe a safe therapeutic approach for KTRs with fractures, unexplained hypercalcemia or bone pain, is the performance of a bone biopsy. The post transplant bone biopsy indication is showed in table 1 .

\section{Antibody to the receptor activator of nuclear factor-kB ligand}

Denosumab is a fully human monoclonal antibody to RANKL that blocks its binding to RANK, inhibiting the development and activity of osteoclasts. Of interest, denosumab is effective at reducing fracture risk and is not associated with an increased in adverse events among patients with impaired kidney function (52).

\section{Bone anabolics}

\section{Teriparatide}

Teriparatide (recombinant human parathyroid hormone 1-34) exerts anabolic effects on the skeleton when given intermittently. The use in osteoporosis pos-transplantation is restricted. One double-blind randomized trial, treated 26 kidney transplant recipients treated with teriparatide (PTH 1-34) or placebo demonstrated that teriparatide does not improve BMD early after kidney transplantation (53). Furthermore, neither histological analysis nor bone markers provide evidence of improved bone turnover or mineralization.

\section{Hormone replacement therapy}

Few studies have approached the replacement of hormone replacement therapy for transplant recipients, most of them showed a protective effect on the skeleton $(54,55)$. It is appropriate to delay HRT initiation until the patient has successfully engrafted, is clinically stable and using reduced dose of most medications (typically 3-6 months post-transplant). Options for hormone replacement therapy include oral and transdermal with the inclusion of either cyclic or continuous progesterone. Mainly in patients with impaired liver function, transdermal route should be advised. Important to note that in younger patients with ovarian insufficiency due to chemotherapy, estrogen replacement also improves menopausal symptoms and improves quality of life.

\section{CONCLUSIONS}

Mineral and bone disorders following organ transplantation are common and characterized by loss of bone volume and mineralization abnormalities leading to osteoporosis and fractures, increased risk of mortality and decreased quality of life. The exposure to high doses of GCs and calcineurin inhibitors is associated with rapid bone loss immediately after transplantation and high fracture incidence. Effective therapies should incorporate either pre-transplant period to treat pre-existing bone diseases and also prevention of bone loss during the first six to 12 months transplantation.

It seems that combination therapy with vitamin $\mathrm{D}$ and bisphosphonates was the most effective regimen to improve BMD of these patients. More studies are needed to examine the effects of different therapeutic interventions on bone disorders after organ transplantation.

Disclosure: Dr. Carolina A. M. Kulak is speaker of Eli-Lilly and GSK. Dr. Melani Custódio is speaker and consultant of AbbVie and Amgen. Dr. Victoria Z. C. Borba is speaker of Sanofi-Aventis, GSK and Eli-Lilly.

\section{REFERENCES}

1. Stein E, Ebeling $P$, Shane E. Post-transplantation osteoporosis. Endocrinol Metab Clin North Am. 2007;36(4):937-63;viii.

2. Kulak CA, Borba VZ, Kulak Júnior J, Campos DJ, Shane E. Posttransplantation osteoporosis. Arq Bras Endocrinol Metabol. 2010;54(2):143-9.

3. Canalis E, Delany AM. Mechanisms of glucocorticoid action in bone. Ann NY Acad Sci. 2002;966:73-81.

4. Kogianni G, Mann V, Ebetino F, Nuttall M, Nijweide P, Simpson H, et al. Fas/CD95 is associated with glucocorticoid-induced osteocyte apoptosis. Life Sci. 2004;75(24):2879-95.

5. Marcén R, Caballero C, Pascual J, Teruel JL, Tenorio M, Ocaña J, et al. Lumbar bone mineral density in renal transplant patients on neoral and tacrolimus: a four-year prospective study. Transplantation. 2006;81(6):826-31.

6. Monegal A, Navasa M, Guañabens N, Peris P, Pons F, Martínez de Osaba MJ, et al. Bone mass and mineral metabolism in liver transplant patients treated with FK506 or cyclosporine A. Calcif Tissue Int. 2001;68(2):83-6.

7. Mclntyre HD, Menzies B, Rigby R, Perry-Keene DA, Hawley CM, Hardie IR, et al. Long-term bone loss after renal transplantation: comparison of immunosuppressive regimens. Clin Transplant. 1995;9(1):20-4.

8. Malluche $\mathrm{HH}$, Monier-Faugere MC, Herberth J. Bone disease after renal transplantation. Nat Rev Nephrol. 2010;6(1):32-40.

9. Dissanayake IR, Goodman GR, Bowman AR, MaY, Pun S, JeeWS, et al. Mycophenolate mofetil: a promising new immunosuppressant that does not cause bone loss in the rat. Transplantation. 1998;65(2):275-8.

10. Bryer HP, Isserow JA, Armstrong EC, Mann GN, Rucinski B, Buchinsky FJ, et al. Azathioprine alone is bone sparing and does not alter cyclosporin A-induced osteopenia in the rat. J Bone Miner Res. 1995;10(1):132-8. 
11. Evenepoel P, Claes K, Kuypers D, Maes B, Bammens B, Vanrenterghem $Y$, et al. Natural history of parathyroid function and calcium metabolism after kidney transplantation: a single-centre study. Nephrol DialTransplant. 2004;19(5):1281-7.

12. Abboud O, Becker G, Bellorin-Font E, Field M, Johnson R, Li PK, et al. KDIGO clinical practice guidelines on hepatitis $C$ in chronic kidney disease acknowledged by ISN. Nat Clin Pract Nephrol. 2008;4(12):648-9.

13. Reichrath J. Dermatologic management, sun avoidance and vitamin $D$ status in organ transplant recipients (OTR). J Photochem Photobiol B. 2010;101(2):150-9.

14. ObiY, Hamano T, Ichimaru N, Tomida K, Matsui I, Fujii N, et al. Vitamin $\mathrm{D}$ deficiency predicts decline in kidney allograft function: a prospective cohort study. J Clin Endocrinol Metab. 2014;99(2):52735.

15. Evenepoel P. Recovery versus persistence of disordered mineral metabolism in kidney transplant recipients. Semin Nephrol. 2013;33(2):191-203.

16. Bonarek $\mathrm{H}$, Merville $\mathrm{P}$, Bonarek $\mathrm{M}$, Moreau K, Morel D, Aparicio $M$, et al. Reduced parathyroid functional mass after successful kidney transplantation. Kidney Int. 1999;56(2):642-9.

17. Reynolds JL, Joannides AJ, Skepper JN, McNair R, Schurgers LJ, Proudfoot $D$, et al. Human vascular smooth muscle cells undergo vesicle-mediated calcification in response to changes in extracellular calcium and phosphate concentrations: a potential mechanism for accelerated vascular calcification in ESRD. J Am Soc Nephrol. 2004;15(11):2857-67.

18. Neves CL, dos Reis LM, Batista DG, Custodio MR, Graciolli FG, Martin Rde $\mathrm{C}$, et al. Persistence of bone and mineral disorders 2 years after successful kidney transplantation. Transplantation. 2013;96(3):290-6.

19. Wolf $M$, Molnar MZ, Amaral AP, Czira ME, Rudas A, Ujszaszi A, et al. Elevated fibroblast growth factor 23 is a risk factor for kidney transplant loss and mortality. J Am Soc Nephrol. 2011;22(5):956-66.

20. Evenepoel P, Lerut E, Naesens M, Bammens B, Claes K, Kuypers $D$, et al. Localization, etiology and impact of calcium phosphate deposits in renal allografts. Am J Transplant. 2009; 9(11):2470-8.

21. Effendy NM, Khamis MF, Shuid AN. Micro-CT assessments of potential anti-osteoporotic agents. Curr Drug Targets. 2013;14(13):1542-51.

22. Isakova T, Wahl P, Vargas GS, Gutiérrez OM, Scialla J, Xie H, et al. Fibroblast growth factor 23 is elevated before parathyroid hormone and phosphate in chronic kidney disease. Kidney Int. 2011;79(12):1370-8.

23. Pinho LR, Ribeiro Santos MJ, Pestana Vasconcelos M. Cinacalcet in the treatment of persistent hyperparathyroidism after kidney transplantation. Clin Nephrol. 2011;75(3):263-8.

24. Mahajan A, Narayanan M, Jaffers G, Concepcion L. Hypoparathyroidism associated with severe mineral bone disease postrenal transplantation, treated successfully with recombinant PTH. Hemodial Int. 2009;13(4):547-50.

25. Lazar ES, Stankus N. Cinacalcet-induced hungry bone syndrome. Semin Dial. 2007;20(1):83-5.

26. Jastrzebski D, Lutogniewska W, Ochman M, Margas A, Kowalski $\mathrm{K}, \mathrm{Wyrwol} \mathrm{J}$, et al. Osteoporosis in patients referred for lung transplantation. Eur J Med Res. 2010;15 Suppl 2:68-71.

27. Franco $C B$, Paz-Filho $G$, Gomes $P E$, Nascimento VB, Kulak $C A$, Boguszewski $\mathrm{CL}$, et al. Chronic obstructive pulmonary disease is associated with osteoporosis and low levels of vitamin D. Osteoporos Int. 2009;20(11):1881-7.

28. Kulak CA, Borba VC, Jorgetti V, Dos Reis LM, Liu XS, Kimmel DB, et al. Skeletal microstructural abnormalities in postmenopausal women with chronic obstructive pulmonary disease. J Bone Miner Res. 2010;9(25):1931-40.
29. Wang TK, O'Sullivan S, Gamble GD, Ruygrok PN. Bone density in heart or lung transplant recipients--a longitudinal study. Transplant Proc. 2013;45(6):2357-65.

30. Spira A, Gutierrez C, Chaparro C, Hutcheon MA, Chan CK. Osteoporosis and lung transplantation: a prospective study. Chest. 2000;117(2):476-81.

31. Dalle Carbonare L, Zanatta M, Braga V, Sella S, Vilei MT, Feltrin $\mathrm{G}$, et al. Densitometric threshold and vertebral fractures in heart transplant patients. Transplantation. 2011;92(1):106-11.

32. Shane E, Rivas M, Staron RB, Silverberg SJ, Seibel MJ, Kuiper J, et al. Fracture after cardiac transplantation: a prospective longitudinal study. J Clin Endocrinol Metab. 1996;81(5):1740-6.

33. Stein EM, Cohen A, Freeby M, Rogers $H$, Kokolus $S$, Scott $V$, et al. Severe vitamin $D$ deficiency among heart and liver transplant recipients. Clin Transplant. 2009;23(6):861-5.

34. Sachdeva R, Soora R, Bryant JC, Seibert JJ, Blaszak RT, Frazier $E A$, et al. Bone mineral status in pediatric heart transplant recipients: a retrospective observational study of an "at risk" cohort. Pediatr Transplant. 2010;14(3):383-7.

35. Tamminen IS, Valta H, Jalanko $H$, Salminen $S$, Mäyränpää MK, Isaksson $\mathrm{H}$, et al. Pediatric solid organ transplantation and osteoporosis: a descriptive study on bone histomorphometric findings. Pediatr Nephrol. 2014 Feb 23. [Epub ahead of print].

36. Hetzer R, Delmo Walter EM. Trends and outcomes in heart transplantation: the Berlin experience. HSR Proc Intensive Care Cardiovasc Anesth. 2013;5(2):76-80.

37. Ninkovic M, Love SA, Tom B, Alexander GJ, Compston JE, et al. High prevalence of osteoporosis in patients with chronic liver disease prior to liver transplantation. Calcif Tissue Int. 2001;69(6):321-6.

38. Guichelaar MM, Kendall R, Malinchoc M, Hay JE. Bone mineral density before and after OLT: long-term follow-up and predictive factors. LiverTranspl. 2006;12(9):1390-402.

39. Monegal A, Navasa M, Guañabens N, Peris P, Pons F, Martinez de Osaba MJ, et al. Bone disease after liver transplantation: a long-term prospective study of bone mass changes, hormonal status and histomorphometric characteristics. Osteoporos Int. 2001;12(6):484-92.

40. Baccaro LF, Boin IF, Pedro AO, Costa-Paiva L, Leal AL, Ramos CD, et al. Decrease in bone mass in women after liver transplantation: associated factors. Transplant Proc. 2011;43(4):1351-6.

41. Premaor MO, Das TK, Debiram I, Parker RA, Ninkovic M, Alexander GT, et al. Fracture incidence after liver transplantation: results of a 10-year audit. QJM. 2011;104(7):599-606.

42. McClune BL, Polgreen LE, Burmeister LA, Blaes AH, Mulrooney DA, Burns LJ, et al. Screening, prevention and management of osteoporosis and bone loss in adult and pediatric hematopoietic cell transplant recipients. Bone MarrowTransplant. 2011;46(1):1-9.

43. Ebeling PR, Thomas DM, Erbas B, Hopper JL, Szer J, Grigg AP, et al. Mechanisms of bone loss following allogeneic and autologous hemopoietic stem cell transplantation. J Bone Miner Res. 1999;14(3):342-50.

44. Polgreen LE, Rudser K, Deyo M, Smith A, Baker KS, Petryk A, et al. Changes in biomarkers of bone resorption over the first six months after pediatric hematopoietic cell transplantation. Pediatr Transplant. 2012;16(8):852-7.

45. Faulhaber GA, Premaor MO, Moser Filho HL, Silla LM, Furlanetto TW. Low bone mineral density is associated with insulin resistance in bone marrow transplant subjects. Bone Marrow Transplant. 2009;43(12):953-7.

46. Grigg AP, Shuttleworth P, Reynolds J, Schwarer AP, Szer J, Bradstock $\mathrm{K}$, et al. Pamidronate reduces bone loss after allogeneic stem cell transplantation. J Clin Endocrinol Metab. 2006;91(10): 3835-43. 
47. D'Souza AB, Grigg AP, Szer J, Ebeling PR. Zoledronic acid prevents bone loss after allogeneic haemopoietic stem cell transplantation. Intern Med J. 2006;36(9):600-3.

48. Miller PD. Diagnosis and treatment of osteoporosis in chronic renal disease. Semin Nephrol. 2009;29(2):144-55.

49. Crawford BA, Kam C, Pavlovic J, Byth K, Handelsman DJ, Angus PW, et al. Zoledronic acid prevents bone loss after liver transplantation: a randomized, double-blind, placebo-controlled trial. Ann Intern Med. 2006;144(4):239-48.

50. Giannini S, D'Angelo A, Carraro G, Nobile M, Rigotti P, Bonfante L, et al. Alendronate prevents further bone loss in renal transplant recipients. J Bone Miner Res. 2001;16(11):2111-7.

51. Shane E, Addesso V, Namerow PB, McMahon DJ, Lo SH, Staron RB, et al. Alendronate versus calcitriol for the prevention of bone loss after cardiac transplantation. N Engl J Med. 2004;350(8):767-76.
52. Jamal SA, Ljunggren O, Stehman-Breen C, Cummings SR, McClung MR, Goemaere $S$, et al. Effects of denosumab on fracture and bone mineral density by level of kidney function. $J$ Bone Miner Res. 2011;26(8):1829-35.

53. Cejka D, Benesch T, Krestan C, Roschger P, Klaushofer K, Pietschmann $P$, et al. Effect of teriparatide on early bone loss after kidney transplantation. Am J Transplant. 2008;8(9):1864-70.

54. Isoniemi H, Appelberg J, Nilsson CG, Mäkelä P, Risteli J, Höckerstedt $\mathrm{K}$. Transdermal oestrogen therapy protects postmenopausal liver transplant women from osteoporosis. A 2-year follow-up study. J Hepatol. 2001;34(2):299-305.

55. Kananen K, Volin L, Laitinen K, Alfthan H, RuutuT, Välimäki MJ. Prevention of bone loss after allogeneic stem cell transplantation by calcium, vitamin $D$, and sex hormone replacement with or without pamidronate. J Clin Endocrinol Metab. 2005;90(7):3877-85. 